DOI: $10.19177 /$ reen.v13e1202027-57

\title{
AVANÇOS RECENTES DO CLUSTER PORTUÁRIO DE ITAJAÍ: UM CLUSTER INOVATIVO?
}

\section{RECENT ITAJAII PORT CLUSTER ADVANCES: AN INNOVATIVE CLUSTER?}

\section{AVANCES RECIENTES DEL CLUSTER PORTUARIO DE ITAJAII: ¿UN CLUSTER INNOVADOR?}

\section{Elisa Maria Moser}

Doutoranda em administração pela Pontifícia Universidade Católica do Rio de Janeiro (PUC-Rio) Endereço: PUC, R. Marquês de São Vicente, n. 225, Gávea, CEP: 22451-900. Rio de Janeiro, RJ, Brasil Telefone: (21) 3527-1001

E-mail: elisamoser@phd.iag.puc-rio.br

\section{Nelson Casarotto Filho}

Doutor em Engenharia de Produção pela Universidade Federal de Santa Catarina (UFSC), com sanduíche na Universidade do Minho - Portugal

Professor na UFSC

Endereço: R. Eng. Agronômico Andrei Cristian Ferreira, s/n, Trindade, CEP: 88040-900. Florianópolis, $\mathrm{SC}$, Brasil

Telefone: (47) 3232-5100

E-mail: nelson.casarotto@ufsc.br

\section{Teresia Diana Lewe van Aduard de Macedo Soares}

Doutorado em Filosofia Econômica, Política e Social Université de Montréal

Professora na PUC-Rio

Endereço: PUC, R. Marquês de São Vicente, n. 225, Gávea, CEP: 22451-900. Rio de Janeiro, RJ, Brasil Telefone: (21) 3527-1001

E-mail: diana@iag.puc-rio.br

Artigo recebido em 10/09/2019. Revisado por pares em 20/11/2019. Reformulado em 21/11/2019. Recomendado para publicação em 01/12/2019. Publicado em 30/04/2020. Avaliado pelo Sistema double blind review. 


\section{RESUMO}

Este estudo tem o objetivo de identificar e analisar o estágio de desenvolvimento do cluster portuário da região de Itajaí em Santa Catarina. A partir do levantamento de informações com especialistas, busca-se caracterizar o grau de desenvolvimento desse cluster utilizando metodologia de Cunha (2002) própria para avaliação de clusters em economias em desenvolvimento. Em vista das recentes transformações, parte-se da suposição de que o cluster possa situar-se no mais alto estágio de desenvolvimento. Confirmamos a utilização do instrumento de coleta para obtenção de um diagnóstico sobre elementos essenciais do cluster, que o posicionou no limiar de um cluster em estágio inovativo.

Palavras-chave: Cluster portuário; Desenvolvimento Regional; Cluster portuário da região de Itajaí.

\section{ABSTRACT}

This study aims to analyze and identify the stage of development of Itajaí port cluster in the South of Brazil. Information was obtained through a survey with experts, that sought to characterize the degree of progress of this cluster using Cunha's (2002) specific methodology to evaluate clusters in developing economies. In view of this cluster recent transformations, it is questioned if Itajaí port cluster could be at the highest stage of development. The study confirmed the use of the collection instrument in obtaining a diagnosis on the essential elements of the cluster, and the results positioned the cluster at the threshold of a cluster in an innovative stage.

Keywords: Port cluster; Regional development; Port cluster in the Itajaí region.

\section{RESUMEN}

Este estudio tiene el objetivo de identificar y analizar el estadio de desarrollo del cluster portuario de la región de Itajaí en Santa Catarina. A partir del levantamiento de informaciones con especialistas, se busca caracterizar el grado de avance de ese cluster utilizando metodología de Cunha (2002) propia para evaluación de clusters en economías en desarrollo. En vista de las recientes transformaciones, se indaga si el cluster portuario de Itajaí puede situarse en la más alta etapa de desarrollo. El estudio confirmó la utilización del instrumento de recolección en la obtención de un diagnóstico sobre elementos esenciales del cluster, posicionándolo muy cerca de un cluster en etapa innovadora.

Palabras clave: Cluster portuário; Desarrollo Regional; Clúster portuario en la región de Itajaí. 


\section{INTRODUÇÃO}

O Brasil possui clusters de reconhecida importância para suas regiões, sendo particular o caso do estado de Santa Catarina, cuja trajetória econômica é marcada por descentralização industrial com distintas especializações setoriais. Essas aglomerações encontram-se em diferentes estágios de evolução, havendo desde polos bastante tradicionais, que remontam ao início do processo de industrialização naquela região, alguns dos quais em declínio, até polos recentes e bastante tecnológicos, que prosperam em uma nova economia de serviços e bens intangíveis.

O objeto do estudo em questão neste artigo é o cluster portuário da região de Itajaí, com um recorte específico sobre as unidades portuárias, que representam competidores na visão da cadeia de produção. Trata-se de uma região que passou por intensa transformação desde o marco legal da modernização dos portos (1993), com o surgimento dos Terminais de Uso Privado (TUPs). Hoje o cluster portuário de Itajaí reúne 4 TUPs e 1 porto público, sendo mediado ao norte pelo polo de São Francisco do Sul, que concentra 1 porto público e 2 TUPs e ao sul pelo polo de Imbituba, com um 1 porto público. Foi na região de Itajaí que surgiu o primeiro TUP do país, e hoje os 6 TUPs de Santa Catarina já representam aproximadamente 60\% da movimentação portuária do estado (ANTAQ, 2018).

O objetivo proposto é o de obter, na avaliação de especialistas, o quanto o cluster portuário de Itajaí se aproxima de um cluster em nível inovativo conforme tipologia de Cunha (2002), apontando os pontos fortes e fracos de seu diagnóstico como cluster. Um cluster pode situar-se, segundo este autor, desde um estágio informal até um estágio inovativo.

As questões que nortearam a pesquisa, visando atingir o objetivo proposto, foram: Em que estágio de desenvolvimento se situa o cluster portuário de Itajaí e como este desenvolvimento se posiciona comparativamente a outros clusters regionais? Quais os fatores positivos de destaque no seu desenvolvimento? Os efeitos positivos recentemente observados nesse cluster são suficientes para caracterizá-lo como em estágio inovativo - o mais alto grau em uma tipologia de desenvolvimento de clusters? Quais aspectos demandam maiores esforços e o que pode ser feito a respeito? 
A relevância deste estudo é apontada em dois aspectos. Em primeiro lugar, destaca-se a utilização do instrumento de coleta para avaliação de um cluster em contexto diferente do setor industrial para o qual foi desenvolvido. Um segundo aspecto refere-se à obtenção de insumos para avaliação do novo modelo de exploração portuária adotado na região.

O método envolveu a opinião de especialistas que avaliaram o cluster portuário de Itajaí, com foco nas unidades portuárias da região e adjascências, a partir de cinco construtos, conforme modelo prescritivo proposto por Cunha (2002).

\section{REFERENCIAL TEÓRICO}

\subsection{CONCEITO DE CLUSTERS}

O termo cluster, como é usualmente empregado no campo de administração, tem o sentido que lhe é atribuído por Michael Porter, no livro The Competitive Advantage of Nations (1990), na qual o autor refere-se à concentração geográfica de empresas e seu impacto na competitividade de uma indústria específica.

Para Enright (1996), o conceito de cluster engloba também a especialização da produção. O autor faz a distinção entre cluster e aglomerados regionais, neste último caso referindo-se também aos fatores da indústria associados, o que envolve compradores e fornecedores, podendo ainda envolver os trabalhadores ou mesmo o canal de distribuição.

Já os distritos industriais, segundo o autor, acrescentam o critério de envolvimento com a comunidade local, onde aparece por exemplo a delimitação de um cluster pela distância da viagem diária dos seus trabalhadores. É assim que são denominadas as aglomerações industriais na Itália, por exemplo. Por fim, ainda distinguindo conceitos próximos, redes de negócios trata de empresas que mantém comunicação e interação entre si, podendo até haver certo nível de interdependência, mas que não necessariamente pertencem a uma mesma indústria ou estejam delimitadas em um espaço geográfico. Em um único cluster pode acontecer de se ter uma ou várias redes de empresas, comumente chamadas, na Itália, de consórcios de empresas (CASAROTTO PIRES, 2001).

Para Lübeck et al. (2012), diferentes conceitos associados a clusters estariam relacionados ao grau de desenvolvimento e integração de seus agentes, e poderiam ser 
elencados nesta ordem: distritos industriais, clusters, arranjos produtivos locais (APL) e sistemas locais de produção e inovação (SLPIs).

Os arranjos produtivos locais (APL) se difeririam de cluster por envolver a articulação de agentes econômicos, políticos e sociais pertencentes à mesma cadeia de produção. Sistemas locais de produção e inovação (SLPI), por sua vez, um estágio mais avançado, decorreriam da alta intensidade dos laços e interações entre todas as empresas estabelecidas na região, de forma a gerar externalidades positivas por meio da criação e introdução de inovações tecnológicas, onde a troca de conhecimentos, produtos e processos são coordenados para alavancar sua competitividade.

Recentemente, muito se tem discutido sobre o declínio do estudo de clusters, mas o que se observa é que o tema ressurge frequentemente associado a novas abordagens, como a economia circular (RAZMINIENE; TVARONAVICIENE, 2018), a de ecossistemas empreendedores (LIGUORI et al., 2018) ou a abordagens dinâmicas sob alguma ótica evolutiva, incluindo a teoria do ciclo de vida da aglomeração e a dinâmica dos sistemas (SALUME; GUIMARÃES; VALE, 2016). Ainda nesses casos, quando a temática gira em torno da competitividade do cluster, o alicerce mais comum ainda é aquele de Porter (1990), em que o dinamismo das trocas internas é motor para aumento da inovação e competitividade de um aglomerado de empresas que supera sua existência isolada.

\subsection{O DIAMANTE DE PORTER E A COMPETITIVIDADE DOS CLUSTERS}

Para Porter (1990), a competitividade do cluster refere-se em grande medida à capacidade das empresas em superar barreiras substanciais a inovação. $\mathrm{O}$ autor desenvolve a relação entre a teoria de agrupamento e a formação da vantagem competitiva por meio de quatro fatores determinantes, que formam um sistema, conhecido como "diamante".

São estes os fatores determinantes da vantagem competitiva citados pelo autor no modelo do diamante:

1. Condição dos Fatores. No contrassenso da premissa de que a vantagem competitiva de uma nação está nos fatores de produção (mão-de-obra, terra, recursos naturais, capital, infraestrutura etc.) herdados, o autor sustenta a tese de que uma economia 
avançada cria os fatores de produção que lhe serão mais importantes, como trabalho especializado ou infraestrutura, necessários à competição em determinada indústria.

2. Condições de Demanda. A natureza da demanda interna de uma indústria é mais importante do que seu tamanho. Isso porque quando a demanda interna decorre de compradores exigentes, ela força a empresa a superar contínuos desafios, sugerindo uma visão clara e precoce das necessidades emergentes do comprador.

3. Indústrias correlatas e de apoio. Outra força competitiva advém da presença de indústrias abastecedoras e indústrias correlatas que sejam internacionalmente competitivas, que podem fornecer métodos de produção competitivos e desencadear inovação e atualização.

4. Estratégia, estrutura e rivalidade das empresas. Essa força refere-se às condições, no país, que governam o modo como as empresas são criadas, organizadas e gerenciadas, bem como a natureza da rivalidade doméstica para estimular a concorrência, criando pressão sobre as empresas para inovar e melhorar.

Figura 1: Determinantes da Vantagem Competitiva Nacional

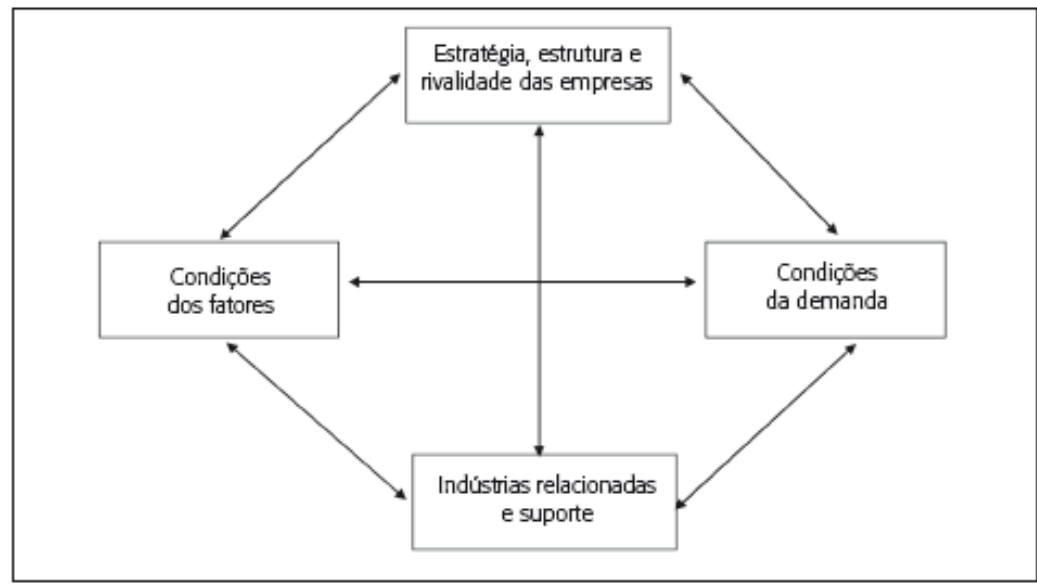

Fonte: PORTER, 1990, p.78

Os quatro fatores acima mencionados constituem o diamante da vantagem competitiva nacional. Cada nação estabelece e opera os fatores para suas indústrias, sendo que a forma como esses fatores interagem reforçando ou influenciando um ao outro para determinar a vantagem competitiva são uma manifestação, segundo o autor, do seu caráter sistêmico. 


\subsection{FATORES E MÉTRICAS DO ESTUDO DE CLUSTER}

Apesar de a competitividade ser um dos temas dominantes das publicações científicas sobre clusters (MASCENA; FIGUEIREDO; BOAVENTURA, 2013), são poucos os artigos que apresentam maiores detalhes sobre os construtos e a operacionalização de variáveis para avaliar essa competitividade.

Assim, podem-se identificar duas linhas de métricas mais comum utilizadas em estudos de clusters. Os autores de uma primeira vertente concentram-se na definição de critérios para identificar a ocorrência de clusters (LÜBECK; WITTMANN; SILVA, 2012; SCHMITZ, 1997; ZELBST; FRAZIER; SOWER, 2010). Já uma segunda vertente, particularmente interessante a esse estudo e que trata de um cluster já identificado, refere-se a métricas para avaliar o estado evolutivo, seja o seu estágio de desenvolvimento alcançado ou ainda a fase do ciclo de vida.

Muitas vezes as métricas utilizadas para reconhecimento do cluster servem também para dar um indicativo de seu desenvolvimento. Lübeck et al. (2012) por exemplo, apontaram capital social, redes de negócios, inovação, políticas públicas, indicadores de concentração territorial e, finalmente, indicadores econômicos locais (IDH, crescimento econômico, desemprego, educação, etc.) como os elementos que influenciam o desenvolvimento de arranjos interorganizacionais, como APLs e SLPIs. Há, nas métricas de identificação de cluster apontadas uma relação entre a competitividade do cluster com o desenvolvimento local e regional.

A fim de avaliar a competitividade do cluster propriamente, destaca-se o trabalho de Mytelka e Farinelli (2000) que compara experiências de clusters industriais tradicionais com outras de desenvolvimento espontâneo da Nigéria, Paquistão, Dinamarca e Itália. As autoras apontaram onze indicadores responsáveis pelas radicais diferenças entre os diferentes estágios de evolução desses aglomerados: atores críticos, tamanho das firmas, inovação, confiança, habilidades, tecnologia, interligações, cooperação, competição, mudanças nos produtos e exportações, e concluíram que a sustentabilidade do cluster está associada a um processo continuado de inovação.

O cluster também pode ser avaliado de acordo com sua origem. Em revisão de literatura elaborada por Barakat et al. (2017), os autores identificam que a gênese do clusters 
pode estar associada a três tipos de dinâmica: (i) fruto de ações governamentais (top-down); (ii) a partir de empresas inicialmente instaladas em uma localidade que atraem novas empresas formando um cluster (bottom-up) e (iii) o cluster pode nascer como resultado do processo interativo entre governo, empresas, universidades, centro de pesquisa, sindicatos e outras instituições de apoio, a que os autores chamam de coevolucionária. Os autores apontam que a principal causa do surgimento de clusters identificada na literatura foi pelo incentivo governamental mas ressaltam para a preponderância dos países asiáticos nesse sentido.

A abordagem bottom-up, por sua vez, é bastante frequente na literatura de empreendedorismo sendo que uma parte significativa dos estudos recentes de cluster no Brasil tem se voltado para avaliação de um ecossistema empreendedor. Nos estudos de Liguori et al. (2018) o ecossistema empreendedor é avaliado por meio de uma escala multidimensional composta de seis domínios específicos estruturais: política, finanças, cultura, apoio, capital humano e mercados. Os autores mostram que para avaliar um ecossistema empreendedor parte-se das mesmas bases de avaliação de cluster, posto que o objetivo em ambos os casos é o crescimento econômico e inovação, embora o trabalho desenvolvido tenha mais o cunho de mostrar o que pode tornar uma região mais ou menos adequada para um ecossistema de novos negócios.

\subsection{ESTÁGIOS DE DESENVOLVIMENTO DO CLUSTER}

Mytelka e Farinelli (2000) avaliam o grau de avanço do aglomerado por meio de uma tipificação composta de três categorias, que valoriza o potencial de mudança dinâmica deles: 
Tabela 1 - Caracterização do estágio de desenvolvimento do cluster

\begin{tabular}{|llll|}
\hline TIPOS & INFORMAL & ORGANIZADO & INOVATIVO \\
\hline Exemplos & Suame Magasine & Nnewi (Nigéria) $^{(1)}$ & Jutland (Dinamarqua) $^{(3)}$ \\
& (Kumasi, Gana) $^{(1)}$ & Sialkot (Paquistão) $^{(2)}$ & Belluno (Itália) $^{(4)}$ \\
Atores críticos & Baixo & Baixo a médio & Alto \\
Tamanho das empresas & Micro e pequenas & Pequenas e médias & Pequenas, médias e grandes \\
Inovação & Pouca & Alguma & Continuada \\
Confiança & Baixa & Alta & Alta \\
Habilidades - qualificação & Baixa & Média & Alta \\
Tecnologia & Baixa & Média & Média \\
Entrelaçamento & Algum & Algum & Extensivo \\
Cooperação & Pouca & Alguma, não sustentada Alta \\
Competição & Alta & Alta & Média a alta \\
Modificações no produto & Pouca ou nenhuma & Alguma & Continuada \\
Exportações & Pequena ou nenhuma & Média - Alta & Alta \\
\hline
\end{tabular}

Fonte: Mytelka e Farinelli (2000), tradução proposta por Cunha (2002).

Os exemplos dos clusters apresentados referem-se a: (1) Autopeças; (2) Instrumentos cirúrgicos; (3) Móveis e; (4) Armações de óculos.

Cunha (2002) propõe, como adaptação para melhor descrever a realidade dos clusters das economias em desenvolvimento, um quarto estágio, anterior ao "Organizado". Assim, a escalada do avanço dos cluster na tipificação desse autor compreende os estágios: informal, intermediário, organizado e inovativo, cada qual representando um quartil em uma escala de 0 a 10. A avaliação considera assim desde um aglomerado onde impera a informalidade até o nível máximo de eficiência voltado para o dinamismo e inovação.

A aplicação do método a seis aglomerados da região de Santa Catarina pelo autor revelou, de acordo com as pontuações obtidas: três aglomerações no estágio organizado: (i) metal-mecânica do norte do Estado $(6,2)$, (ii) móveis de São Bento do Sul, Rio Negrinho e Campo Alegre $(5,2)$ e (iii) de cerâmica de revestimento, próximo a Criciúma $(5,1)$. Entre os aglomerados de estágio intermediários, classificaram-se dois: (i) o de têxteis e de vestuário, na região de Blumenau e Brusque $(4,1)$ e (ii) de plásticos, no sul do Estado $(3,2)$. Por fim, caracterizado como aglomerado informal, houve apenas o de vestuário do Sul $(2,0)$. A despeito da tradição de clusters neste estado, não foi identificado, segundo Cunha (2002), em estudo utilizando tipologia própria, àquele tempo, nenhuma aglomeração com a caracterização de inovativo no estado de Santa Catarina.

A partir das alterações propostas por Cunha, e introduzindo algumas modificações consideradas relevantes para o estudo em questão, foram definidos os principais aspectos a 
serem avaliados a partir dos cinco construtos, com quatro estágios de desenvolvimento de clusters, conforme apresentado a seguir:

Tabela 2 - Caracterização do estágio de desenvolvimento do cluster para economias em desenvolvimento

\begin{tabular}{|c|c|c|c|c|}
\hline CONSTRUTOS & INFORMAL & INTERMEDIÁRIO & ORGANIZADO & INOVATIVO \\
\hline $\begin{array}{l}\text { A. REPRESENTATIVIDADE / RELEVÂNCIA } \\
\text { Contexto da Relevância } \\
\text { Centralidade do Cluster } \\
\text { Qualificação dos Atores Críticos }\end{array}$ & Pouca ou nenhuma & Média / Baixa & Média / Alta & Alta \\
\hline $\begin{array}{l}\text { B. DESEMPENHO } \\
\text { Dinamismo Industrial } \\
\text { Exportações } \\
\text { Lucratividade } \\
\text { Competição Externa }\end{array}$ & Pouca ou nenhuma & Média / Baixa & Média / Alta & Alta \\
\hline $\begin{array}{l}\text { C. COOPERAÇÃO (propensão a) e GOVERNANÇA } \\
\text { Confiança } \\
\text { Competição/ Rivalidade } \\
\text { Atmosfera Industrial } \\
\text { Papel da Cultura } \\
\text { Governança } \\
\text { Competição Externa }\end{array}$ & Pouca ou nenhuma & Média / Baixa & Média / Alta & Alta \\
\hline $\begin{array}{l}\text { D. ENTRELAÇAMENTO / INTEGRAÇÃO } \\
\text { Integração Técnico-Produtivo } \\
\text { Desenvolvimento de Fatores } \\
\text { Integração Tecnológico-Informação } \\
\text { Suporte de Instituições }\end{array}$ & Pouca ou nenhuma & Média / Baixa & Média / Alta & Alta \\
\hline $\begin{array}{l}\text { E. EFEITOS RESULTANTES DA AGLOMERAÇÃO } \\
\text { Vantagens passivas ou de mera aglomeração } \\
\text { Ganhos derivados de ação conjunta (passivo) }\end{array}$ & Pouca ou nenhuma & Média / Baixa & Média / Alta & Alta \\
\hline
\end{tabular}

Fonte: Elaborado pelos autores (2019).

Para Salume, Guimarães e Vale (2016), a maior parte dos estudos de clusters está pautada em aspectos estáticos que não avaliam a variação da trajetória de desenvolvimento ao longo do tempo. Os autores propõem assim a adoção da abordagem dinâmica de clusters, seja pela via do ciclo de vida e dependência da trajetória, ou pela utilização do system dynamics (dinâmica de sistema).

Avaliar a tabela acima de caracterização do estágio de desenvolvimento do cluster sob a perspectiva de ciclo de vida tende a ser uma contribuição relevante. Isso porque o cluster em estágio avançado não necessariamente vai manter essa posição indefinidamente, a depender se o cluster entra em um ciclo virtuoso ou vicioso.

O ciclo vicioso pode ser gerado quando as interações entre os pilares produzem lockins que são de natureza política (relacionado às redes e ao contexto), cognitiva (inerente à ação) e funcional (relativo à ação e contexto). Em contraste, o ciclo virtuoso é obtido quando da relação entre os elementos emergem efeitos positivos, tais como interação e ação de agentes diversificados, circulação de conhecimento e difusão de ideias que gerem inovações (SALUME; GUIMARÃES; VALE, 2016, p. 126) 
Para tanto, a fim de verificar a trajetória do cluster, esses autores recomendam a escolha de variáveis que devem depender diretamente da indústria em que o cluster atua e das condições ambientais que permeiam o negócio, a fim de identificar, em cada etapa, as variáveis intervenientes no processo de desenvolvimento, estagnação ou declínio do cluster.

Esse estudo teve por base o modelo de Cunha (2002), escolha que se justifica principalmente por: (1) ter sido um modelo adaptado para economias em desenvolvimento; (2) ter sido já utilizado para avaliar seis clusters de Santa Catarina, o que permite a análise comparativa do cluster portuário da região de Itajaí com outros clusters da região; (3) ter sido desenvolvido com uma escala que aponta elementos de competitividade e inovação, compatível com o conceito de competitividade de Porter (1990) que foi a base teórica desse estudo.

\subsection{O CLUSTER PORTUÁRIO DE ITAJAÍ}

A exploração dos portos está definida na Constituição Federal de 1988 como matéria de competência da União (art. 21), sendo a legislação portuária matéria de competência privativa da União (art. 22). Tais preocupações revelam a dimensão e importância deste setor, considerado estratégico para o país.

Até 1990, a organização do setor no Brasil ocorria por meio da Empresa de Portos do Brasil S.A. - PORTOBRÁS, uma holding vinculada ao Ministério dos Transportes. Após sua extinção, foi promulgada a Lei no 8.630, de 25 de janeiro de 1993, que passou a ser conhecida como Lei de Modernização dos Portos, considerada um verdadeiro marco na reformulação do setor.

A partir das alterações legais estabelecidas, o governo passou o controle dos portos às administrações portuárias estaduais e às Companhias Docas, buscando paralelamente o apoio e investimento do setor privado por meio de concessões e arrendamentos.

Em 2013, ocorre outro marco regulatório importante no setor, com a liberação de instalações portuárias fora da área do porto organizado, que pode ser concedida mediante autorização prévia da Agência Nacional de Transportes Aquaviários (ANTAQ), conforme definido na Lei no 12.815/2013 e Decreto no 8.033/2013. Nesse caso, potenciais interessados 
passaram a poder apresentar suas propostas e, após autorização, receberam o direito de explorar a atividade portuária.

De acordo com a nova legislação, os modos de exploração podem ser via concessão e arrendamento de bem público ou por meio de autorização para exploração indireta, que, em função do tipo de carga podem ser Terminais de Uso Privado (TUP), Estações de Transbordo de Carga (ETC), Instalações Portuárias de Turismo (IPT) e Instalações Portuária de Pequeno Porte (IP4).

O Terminal de Uso Privado é uma instalação portuária explorada mediante autorização, localizada fora da área do porto organizado, tendo sido crescente sua importância para o país desde então.

Atualmente, Santa Catarina possui 6 Terminais de Uso Privado (TUP) e 3 portos públicos, sendo que, desde 2012, a movimentação em portos privados é superior ao volume de movimentação dos portos públicos (ANTAQ, 2018). Em termos de volume total, os portos catarinenses representam menos de $4 \%$ da movimentação do Brasil. Já quando considerado apenas o volume em carga conteinerizada, Santa Catarina representa cerca de $18 \%$ do total movimentado no país (ANTAQ, 2018) em uma clara evidência da vocação portuária desta região, em especial a região de Itajaí. Em termos de cargas gerais, as unidades portuárias da região de Itajaí foram responsáveis por $26 \%$ da movimentação de Santa Catarina. Já quando considerada a movimentação de conteiners, as mesmas unidades representam cerca de $60 \%$ do total movimentado.

Em 2017, foi movimentada cerca de 1 bilhão de tonelada de carga bruta no Brasil e, com uma participação que vem se mantendo relativamente estável, os terminais privados representaram cerca de $65 \%$ do total movimentado (ANTAQ, 2018).

Tendo em vista o crescimento recente do complexo portuário de Itajaí a partir da configuração dos TUPs, apoiado em características como alta eficiência e produtividade, destaca-se também a contribuição deste cluster para o desenvolvimento econômico e social da região. 
No Complexo Portuário, o destaque são as cargas conteinerizadas, sendo que 2018 registrou uma movimentação acumulada do ano de 1.150.587 TEUs com 11.774.192 toneladas, um crescimento de $3 \%$ em relação ao mesmo período do ano anterior que registrou 1.119.271 TEUs com 11.366.191 toneladas (PORTO DE ITAJAí - AUTORIDADE PORTUÁRIA, 2018).

Gráfico 1 - Desempenho Complexo Portuário de Itajaí em TEUs

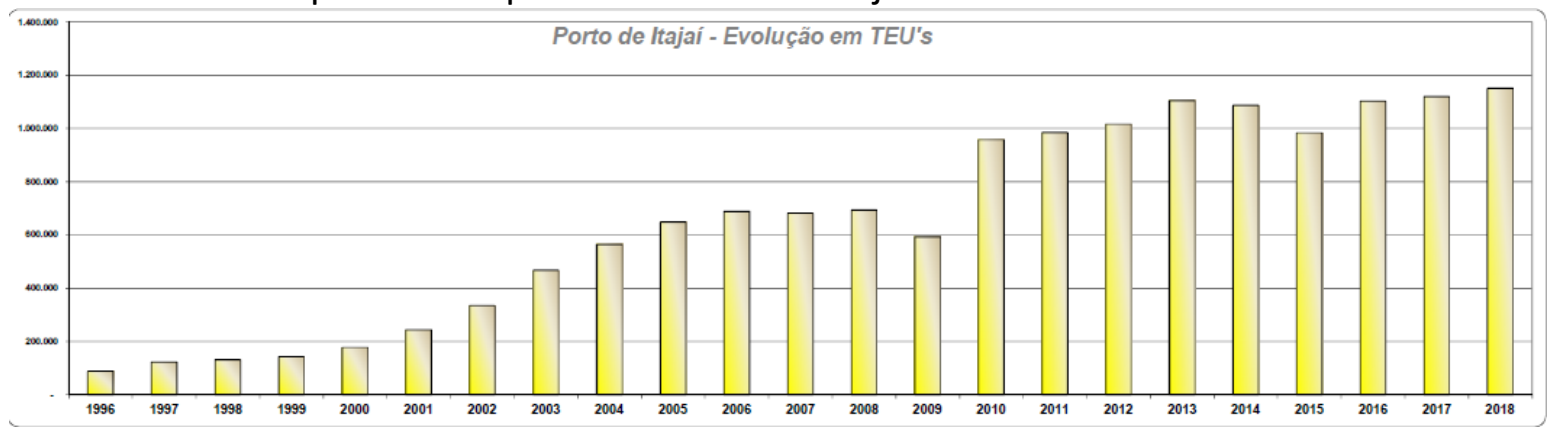

Fonte: PORTO DE ITAJAÍ - AUTORIDADE PORTUÁRIA, 2018 - Relatório Estatístico do Complexo Portuário de Itajaí (dez/2018)

O Complexo Portuário de Itajaí possui como autoridade portuária uma autarquia municipal, a Superintendência do Porto de Itajaí. Trata-se de uma importante via de comércio exterior de Santa Catarina, que teve seu surgimento propiciado pela localização na Foz do Rio Itajaí-Açu mas hoje conta com conjuntura de estaleiros, indústria naval e pesqueira que se desenvolveu nos entornos da região, além de importantes indústrias exportadoras. Por essa proximidade, o complexo pode ser definido na concepção de um porto-indústria (CABRAL, 2014), termo utilizado para caracterizar a formação de clusters próximos a portos marítimos, especialmente de empresas industriais fortemente ligadas ao mercado internacional, que sejam intensivamente utilizados para escoamento da produção ou recebimento de seus insumos.

O complexo está inserido em 10 linhas de navegação de longo curso e 3 linhas de cabotagem, que o interligam com 24 países de origem e destino de cargas conteinerizadas e com dez portos brasileiros (DATAMAR, 2017).

Sobre os estaleiros de construção naval localizados, Pinto (2016) destaca a presença de NavShip, maior fabricante brasileiro de navios de apoio a plataforma offshore - PSV, a Detroit Brasil, o Estaleiro Oceana e o Estaleiro Keppel Fels Brasil, Oceana, Keppel Singmarine Brasil, Zemar, Detroit e Navship, entre outros menores, além de estaleiros de fabricação de 
embarcações de dragagem, embarcações de trabalho diversos e de pesca profissional de madeira (traineiras) e estaleiros de fabricação de embarcações de recreio.

A região conta também com sócios-armadores de destaque nos terminais de contêineres, sendo a Maersk Line, por meio da APM Terminals, no Porto Público e a MSC por meio do grupo acionista Terminal Investment Limited (TIL), no TUP Portonave, ambos reconhecidamente grandes players do mercado internacional de navegação de contêineres (MINISTÉRIO DA INFRAESTRUTURA, 2018).

Na região de Itajaí e Navegantes situa-se também um dos mais importantes parques industriais pesqueiros do país, o que leva o estado ao maior produtor nacional de pescado de origem marinha. A região concentra as operações de descarga de mais de 600 embarcações de porte industrial.

Apesar da importância econômica da região portuárias associada a essas indústrias correlatas, as principais críticas hoje dizem respeito à qualidade dos barcos pesqueiros da região, ainda feitos de madeira (RENCK, 2014) e à infraestrutura viária insatisfatória no entorno portuário do município de Navegantes (MINISTÉRIO DA INFRAESTRUTURA, 2018).

O principal conflito observado na relação porto-cidade refere-se à influência do Complexo Portuário na mobilidade urbana dos municípios de Itajaí e Navegantes, já que o Porto Público e os TUPs estão localizados em área urbanizada. (...) De maneira geral, o fator que contribui para a formação de gargalos nos acessos do entorno do Complexo Portuário de Itajaí é o intenso fluxo de veículos com destino aos municípios de Itajaí, Navegantes e cidades vizinhas, conflitando com os veículos de carga que se dirigem ao Complexo (MINISTÉRIO DA INFRAESTRUTURA, 2018, p. 53).

Parte-se da possibilidade de haver, no cluster portuário de Itajaí, características relativas a um cluster inovativo, o nível mais avançado de desenvolvimento segundo uma tipologia própria para classificação de clusters em economias em desenvolvimento. Este trabalho, como já ressaltado, tem como objetivo obter, na avaliação de especialistas, o quanto o cluster portuário de Itajaí se aproxima de um cluster em nível inovativo conforme tipologia de Cunha (2002), apontando os pontos fortes e fracos de seu diagnóstico como cluster. 


\section{METODOLOGIA}

Quanto à abordagem teórica, os estudos de cluster levantados por Mascena et al. (2013) foram classificados em empíricos, teóricos ou teórico-empíricos. Considerado essa classificação, o estudo realizado teve como proposta uma abordagem metodológica teóricoempírica. Em termos empíricos, buscou-se identificar o estágio de desenvolvimento do cluster portuário de Itajaí. Em termos teóricos, foi realizada uma revisão de literatura sobre o tema, de forma a poder corroborar ou refutar aspectos da teoria com base nos achados empíricos. Para tanto, foram utilizadas tanto teorias relativas à competitividade do cluster quanto à tipologia de classificação de desenvolvimento de cluster.

Em relação ao nível de pesquisa, trata-se de uma pesquisa descritiva, na medida em que se pretendeu detalhar uma realidade. Como delineamento de pesquisa, tratou-se de uma survey. Gil (2008) apresenta três formas de levantamento de dados: a entrevista, o formulário, e o questionário.

Para o presente estudo, utilizou-se questionário em formulário online, enviado aos respondentes por meio do servidor Qualtrics, método de coleta de dados que pode ser classificado, segundo Mattar (2014), como questionário auto-preenchido, em que o pesquisado lê o instrumento e o responde diretamente sem a intervenção do entrevistador. Com vistas a obter respostas objetivas dos respondentes, privilegiou-se o uso de questões de múltipla escolha. Questões abertas foram utilizadas de forma a complementar as respostas objetivas.

Para cumprir com o objetivo proposto, o principal requisito do estudo esteve na seleção dos pesquisados. Mantendo a coerência com o método de pesquisa utilizado por Cunha (2002), a amostra contempla seis respondentes qualificados para a pesquisa. Uma amostra representativa, neste caso, implicou em selecionar profissionais que demonstrassem profundo conhecimento ou experiência do objeto de estudo, ou seja, do cluster portuário de Itajaí, provenientes do meio acadêmico, empresarial ou governamental.

Diante dessa necessidade de composição de uma amostra qualificada, elegeu-se o processo de amostragem não probabilística, método considerado adequado quando a seleção dos elementos depende de algum tipo de interferência do pesquisador ou do entrevistador. 
Malhotra (2005) caracteriza quatro técnicas de amostragem não probabilística: por conveniência, por julgamento (ou intencional), por quotas ou bola de neve.

Utilizou-se a amostragem intencional ou por julgamento, em que o pesquisador define uma amostra específica a ser entrevistada, em função de determinados critérios da pesquisa. Segundo Oliveira (2001), a amostragem não probabilística intencional é comumente empregada nas situações a seguir:

- para consultar experts (profissionais especializados) em um dado tema;

- quando é necessário incluir um pequeno número de unidades na amostra;

- quando é preciso obter uma "amostra deliberadamente enviesada".

Costa Neto (1977) afirma que, nas amostras intencionais, enquadram-se os diversos casos em que o pesquisador deliberadamente escolhe certos elementos para pertencer à amostra, por julgar que tais elementos são bem representativos da população. Ainda, podese ressaltar que, para determinados casos, a amostra por julgamento pode ser mais fidedigna e representativa do que uma amostra probabilística (OLIVEIRA, 2001).

Utilizando a rede pessoal dos autores, foi obtida uma amostra representativa de seis respondentes qualificados para o tema de estudo, conforme descrições a seguir:

- $\quad$ Respondente 1, graduado em Logística (Universidade do Vale do Itajaí), com especialização em Gestão Empresarial e Logística, atua na área comercial da empresa Portonave S/A com experiência de 12 anos no setor portuário da localidade Itajaí/Navegantes.

- $\quad$ Respondente 2, graduado em Engenharia Civil pela Poli/USP, com mestrado em Engenharia de Transportes pela COPPE/URFJ e Doutorado em Administração com ênfase em logística pelo Instituto Coppead/UFRJ. Atua como analista setorial no BNDES, Departamento de Logística e Transportes. Trabalha no setor portuário há cerca de 15 anos por meio de projetos de consultoria e nas atividades de financiamento e apoio ao financiamento no setor.

- Respondente 3, gestor de comércio exterior, especializado na área de despacho aduaneiro, atua há 23 anos no segmento, localizado em Itajai-SC 
- $\quad$ Respondente 4, graduado em Administração com Habilitação em Comércio Exterior pela Universidade do Vale do Itajaí UNIVALI, atua na área Comercial como Gerente Comercial. Possui experiência de mais de 20 anos no segmento de Logística de Comércio Exterior, atuando com o complexo portuário da Foz do Rio Itajaí.

- Respondente 5, técnico de Nível Superior, Superintendente Interino [Superintendência do Porto de Itajaí, autarquia municipal da Prefeitura de Itajaí], com experiência de mais de 20 anos na área portuária.

- Respondente 6, graduada em economia (Universidade UFRGS), com especialização em Maritime Economics and Logistics pela Erasmus de Roterdã), atua na área de estratégia da empresa Porto Itapoá com experiência de 6 anos no setor portuário no Brasil, avaliando viabilidade de projetos do Norte ao sul do País

Ressalta-se que a utilização do instrumento de coleta e verificação de sua aplicabilidade também constituía um dos objetivos do estudo. O questionário adotado seguiu em grande medida o modelo prescritivo de Cunha (2002) baseado em cinco dimensões: 1. Representatividade e Relevância, 2. Desempenho, 3. Cooperação e Governança, 4. Entrelaçamento e Integração, 5. Efeitos Resultantes da Aglomeração Geográfica.

As questões de cada pergunta apontavam para a presença de fatores de cada um desses construtos em níveis baixo, médio ou alto. A partir da média das notas, cada dimensão recebeu uma classificação gradativa, em uma escala de 0 (zero) a 10 (dez).

Ainda, em observância ao procedimento estabelecido por Cunha (2002) quando da propositura do modelo, o enquadramento em cada uma das cinco dimensões obedeceu ao seguinte critério: baixo/fraco, notas até 3,3; médio, notas de 3,4 a 6,7 e alto/elevado, de 6,8 a dez.

Com a média da nota final nessas cinco dimensões, o cluster foi então classificado, conforme metodologia do autor, em uma das quatro categorias da tipologia de classificação de clusters: de 0 a 2,5 - informal; de 2,6 a 5 - intermediário; de 5,1 a 7,5-organizado e de 7,6 a 10 - inovativo. Com isso, além de identificar o estágio de desenvolvimento, é possível apontar os pontos fortes e fracos da evolução desse cluster. 
Destaca-se que, como resultado do método de pesquisa adotado, os resultados refletem as percepções dos especialistas que compõem a amostra. Tal amostra foi constituída de forma deliberada, composta por profissionais que, no julgamento dos autores, representavam adequadamente conhecimentos e vivências relacionadas ao objeto de estudo. Como limitações do método, destaca-se que os resultados são não-generalizáveis e não há um teste de hipótese.

Conforme enunciado por Levine, Berenson \& Stephan (2005) amostras não probabilísticas podem oferecer certas vantagens, tais como conveniência, velocidade e baixo custo. Entretanto, os autores recomendam sua aplicação exclusivamente para estudos em pequena escala que precedam grandes investigações, uma vez que, em decorrência de vieses de seleção, podem carecer de precisão.

Tendo em vista que o estudo proposto surgiu da necessidade de obter um primeiro diagnóstico sobre o cluster portuário, em uma visão rápida e preliminar, os autores julgaram que o método de amostragem não probabilístico foi adequado. Principalmente, em vista da seleção específica dos entrevistados, o método mostrou-se bastante rico pois a intencionalidade, conforme explicado por Gil (2008I), pode tornar a pesquisa mais rica em termos qualitativos, proporcionando os elementos necessários para a identificação de uma dinâmica que ocorre na realidade.

\section{RESULTADOS DA PESQUISA}

\subsection{CARACTERIZAÇÃO DO CLUSTER PORTUÁRIO DE ITAJAÍ}

\subsubsection{Representatividade e Relevância}

Dentre as alternativas de abrangência para importância do cluster, local, nacional ou internacional, a maior parte dos pesquisadores apontou que o cluster portuário de Itajaí está inserido em um contexto de relevância nacional. No que se refere à organização interna, predomina a alta centralidade, ou seja, existem unidades portuárias centrais ao redor das quais há intensa participação das demais.

Destaca-se a alta qualificação dos atores críticos, que na visão quase unânime dos especialistas, posiciona a experiência das unidades portuárias em um sistema técnico- 
produtivo mais complexo e mais próximo da fronteira mundial, em que prevalecem padrões de gestão avançados.

Outros destaques do cluster citados pelos especialistas referem-se à relevância no segmento de cargas conteinerizadas, eficiência tecnológica das operações e aglomeração de empresas nos arredores do porto, que contribuem para sua relevância. Assim, sobre a representatividade do cluster portuário de Itajaí, os especialistas consideraram ainda importante destacar:

[sua] "Forte atuação no segmento de cargas conteinerizadas com alto valor agregado"

"O cluster portuário de Itajai conta com tecnologia e equipamentos de ponta, celeridade nas operações das embarcações que por aqui operam bem como possui como suporte uma excelente estrutura retroportuaria, localização estratégica e completa gama de serviços logísticos."

"O Porto de Itajaí tem mais de 70 anos, durante sua existência atraiu inúmeras empresas de serviços logísticos e indústrias, as quais dependem do setor portuário. São as empresas instaladas ao redor do Porto que ainda o colocam numa posição de destaque no Brasil, pois canal de acesso marítimo (necessidade constante de dragagem) e acesso terrestre (Porto está apertado dentro da cidade) já limitam o crescimento do porto"

As considerações tecidas pelo respondente acima sobre alta relevância do cluster portuário estão em linha com os achados da literatura. A interação do porto com as indústrias da região foi destacada por Francisco e Botter (2017) ao explicarem os movimentos que ensejam o crescimento recente do complexo portuário de Itajaí:

Os TUP vêm se mostrando uma importante ferramenta para tornar o setor portuário brasileiro mais produtivo. Porém, se não houver, por parte do governo, mecanismos com critérios bem definidos e planejados 
para autorizar ou negar os pedidos de novos terminais, os impactos negativos atingirão tanto essas empresas quanto o próprio sistema portuário. (FRANCISCO \& BOTTER, 2017, p. 142)

Destaca-se, como ponto crítico desta dimensão, o necessário reforço de planejamento para integração portuária logística (PAOLIELLO, 2014), uma das preocupações advindas do novo marco legal, a fim de manter o nível atual de competitividade, como destacado pelo autor a seguir:

Além do aperfeiçoamento do marco regulatório, há a necessidade de melhor articulação e integração da logística portuária à logística rodoviária e ferroviária de acesso aos portos, sem as quais os problemas atualmente enfrentados por aqueles que necessitam movimentar suas cargas pela via marítima ou lacustre correm o risco de se perpetuarem por mais uma geração legal (PAOLIELLO, 2014, p. 48).

\subsubsection{Desempenho}

Em 2017, os terminais privados foram responsáveis por $57 \%$ do total de 42,6 milhões de toneladas movimentados pelas instalações portuárias de Santa Catarina, segundo dados da ANTAQ (2018). Deste total, o complexo portuário de Itajaí participou com a movimentação de cerca de 11 milhões de toneladas, sendo Terminal Portonave, 79\%, Itajaí (Cais Arrendado), 19\%, Terminal Portuário Braskarne, 1\% e em menor proporção Teporti e Poly Terminais Portuários.

No segmento específico de cargas conteinerizadas, os terminais do complexo de Itajaí respondem por $59 \%$ do total da movimentação de Santa Catarina enquanto esse estado é responsável por cerca de $17 \%$ da carga de contêineres movimentada no Brasil, representatividade mantida relativamente estável nos últimos anos (ANTAQ, 2018). 
Tabela 3 - Movimentação recente dos terminais portuários catarinenses

\begin{tabular}{|c|c|c|c|c|c|c|c|c|}
\hline Terminal & Tipo de instalação & Complexo Portuário & 2017 & 2016 & 2015 & 2014 & 2013 & 2012 \\
\hline São Francisco Do Sul (Cais Público) & Porto Público & São Francisco do Sul & 9.600 .583 & 8.237 .018 & 10.840 .615 & 10.163.706 & 9.959 .842 & 7.984 .676 \\
\hline Portonave - Terminais Portuários De Navegantes & Porto Privado & Itajaí & 8.780 .326 & 9.650 .564 & 7.585 .704 & 7.849 .790 & 7.569 .404 & 5.920 .600 \\
\hline Terminal Aquaviário De São Francisco Do Sul & Porto Privado & São Francisco do Sul & 8.354 .117 & 8.543 .531 & 10.219 .206 & 10.525 .752 & 10.360 .427 & 10.274 .072 \\
\hline Porto ltapoá Terminais Portuários & Porto Privado & São Francisco do Sul & 6.876 .837 & 6.296 .500 & 6.289 .380 & 5.521 .786 & 5.645 .765 & 3.131 .798 \\
\hline Imbituba (Cais Público) & Porto Público & Imbituba & 4.486 .407 & 4.803 .186 & 3.391 .084 & 3.364 .439 & 2.492 .026 & 2.055 .612 \\
\hline São Francisco Do Sul (Tesc) & Porto Público & São Francisco do Sul & 2.170 .749 & 1.845 .722 & 2.273 .812 & 3.104 .629 & 3.069 .983 & 2.949 .829 \\
\hline Itajaí (Cais Arrendado) & Porto Público & Itajaí & 2.082 .037 & 1.860 .703 & 3.090 .722 & 3.598 .594 & 3.639 .630 & 3.597 .454 \\
\hline Terminal Portuário Braskarne & Porto Privado & Itajaí & 130.215 & 135.208 & 127.902 & 212.072 & 227.201 & 176.879 \\
\hline Teporti & Porto Privado & |tajaí & 91.528 & 64.708 & 72.656 & 286.993 & 423.996 & 183.113 \\
\hline Poly Terminais Portuários & Porto Privado & Itajaí & 41.521 & 12.304 & 6.993 & 0 & 0 & 0 \\
\hline Total Movimentação ( $t$ ) & & & 42.614 .320 & 41.449 .446 & 43.898.074 & 44.627.761 & 43.388.275 & 36.274 .032 \\
\hline Participação Portos Privados & & & $57 \%$ & $60 \%$ & $55 \%$ & $55 \%$ & $56 \%$ & $54 \%$ \\
\hline Participação Complexo Portuário de ltajaí & & & $26 \%$ & $28 \%$ & $25 \%$ & $27 \%$ & $27 \%$ & $27 \%$ \\
\hline
\end{tabular}

Fonte: Dados ANTAQ (2018).

No quesito desempenho, o dinamismo industrial do cluster mostrou-se elevado, na opinião dos especialistas, com crescimento produtivo e lucratividade superior à média industrial catarinense nos últimos 5 anos. Já o crescimento das exportações acompanha o próprio ritmo do dinamismo da indústria catarinense.

Interessante notar o efeito percebido da competição externa na opinião dos especialistas. Na soma dos efeitos, que considera o benefício advindo da abertura no contexto internacional com recursos e rotas, apesar da intensa rivalidade, o resultado da soma dos fatores foi avalido como positivo para o desempenho do cluster.

O papel do governo, nesse caso, por meio da Lei da Modernização dos Portos, foi contribuir para promover a rivalidade que cria pressão sobre as empresas para inovar e melhorar, conforme a dinâmica de forças do sistema do diamante competitivo de Porter (1990).

A política comercial do governo deve buscar o acesso aberto ao mercado em todas as nações estrangeiras. (...) A vantagem competitiva surge da liderança que utiliza e amplia as forças do diamante para promover a inovação e a atualização. Aqui estão apenas alguns tipos de políticas que apoiarão o esforço: criar pressão pela inovação, (...), buscar os concorrentes mais capazes como motivadores. Para motivar a mudança organizacional, concorrentes capazes e rivais respeitados podem ser um inimigo comum. Os melhores gestores sempre administram um pouco assustados; eles 
respeitam e estudam concorrentes (PORTER, 1990, p. 89, tradução nossa).

\subsubsection{Cooperação (propensão) e Governança}

$\mathrm{Na}$ avaliação da propensão à cooperação e o desenvolvimento da governança no interior do cluster, há aspectos contraditórios. De um lado, nota-se o reconhecimento de uma atmosfera positiva pela percepção compartilhada de importância do cluster e aspectos culturais favoráveis; de outro, a competição acirrada parece desestabilizar as relações.

Para a maioria dos respondentes, a confiança entre as unidades portuárias é média, com restrições dadas pela incerteza em relação ao comportamento dos demais atores do aglomerado.

O clima de envolvimento formado pela consciência da importância do cluster foi considerado elevado, e para a maioria dos respondentes, há alguma contribuição cultural positiva advinda da tradição em associativismo e em cooperação. $O$ efeito da concorrência externa por outro lado teria levado à deterioração das relações, que tornam a competição mais acirrada, de forma que a alta rivalidade levou a maioria dos respondentes a apontar um clima de "guerra comercial" sobre as relações no interior do cluster.

Apesar de defender que a cooperação direta entre os rivais da mesma indústria seja fortemente limitada, Porter (1990) enuncia que esforços cooperativos podem ser benéficos para o diamante competitivo da nação, especialmente em áreas como pesquisa, quando indiretos e mediados por instituições independentes:

Sob certas condições limitadas, a pesquisa cooperativa pode ser benéfica. Os projetos devem estar em áreas de pesquisa básica de produtos e processos, não em assuntos intimamente relacionados às fontes de vantagem proprietárias de uma empresa. Eles devem constituir apenas uma parte modesta do programa geral de pesquisa de uma empresa em qualquer campo. A pesquisa cooperativa deve ser apenas indireta, canalizada através de organizações independentes às quais a maioria dos participantes do setor tem acesso. Estruturas 
organizacionais, como laboratórios universitários e centros de excelência, reduzem os problemas de gerenciamento e minimizam o risco de rivalidade. Finalmente, os projetos cooperativos mais úteis geralmente envolvem campos que afetam vários setores e exigem investimentos substanciais em P\&D (PORTER, 1990, p. 88, tradução nossa).

Para Schmitz (1997), a eficiência coletiva não exclui a existência de conflito ou competição entre as empresas do cluster, sendo inclusive parte da força motriz da competitividade.

Ou, nas palavras do autor:

Mesmo naqueles lugares onde despontou uma capacidade coletiva para competir, adaptar e inovar, é importante não se esperar uma ilha de unidade e de solidariedade. A eficiência coletiva é produto de um processo interno, em que algumas empresas crescem e outras declinam (SCHMITZ, 1997, p.170).

\subsubsection{Entrelaçamento / Integração}

Não há uma caracterização clara quanto ao nível de verticalização do sistema produtivo. Alguns especialistas apontaram descentralização do sistema produtivo com forte divisão de trabalho, enquanto outros citaram que esse era o caso de apenas de portos mundiais que deveriam servir de exemplo:

Talvez seja interessante estudar a dinâmica da instalação de terminais de contêineres mundialmente pq [porque], ao que parece, respeitam uma lógica de verticalização (armador - terminal, veja o caso da BTP em Santos, por ex.) ou diversificação de ativos de grandes redes internacionais, como Dubai Ports, por exemplo.

Quanto à integração dos fatores de produção, a maioria dos respondentes apontou que há ações para desenvolvimento comum, embora não seja verificada alta troca de informações entre as unidades portuárias visando ao aprendizado coletivo. 
Além disso, quase todos os respondentes afirmaram que o suporte institucional ao cluster é médio, sendo o apoio predominantemente recebido por determinadas unidades portuárias.

A esse ponto, cabe destacar que um bom nível de entrelaçamento deve envolver também a participação mais ativa da comunidade de partes interessadas, os diferentes stakeholders, que de alguma forma quando envolvidos por meio de mecanismos participativos de tomada de decisões podem prestar contribuições efetivas para o desenvolvimento do cluster, o que vem se tornando especialmente comum em agendas de sustentabilidade (BENITES-LAZARO; MELLO-THÉRY, 2019).

\subsubsection{Efeitos Resultantes da Aglomeração Geográfica}

Os ganhos derivados da concentração geográfica das empresas, percebidos pelos especialistas, circunscrevem-se a vantagens passivas resultantes da aglomeração como vantagens decorrentes da disponibilidade de mão-de-obra, menor custo de matérias-primas e de alguns serviços básicos especializados. Não foram reconhecidos grandes projetos de ação conjunta no sentido de troca de informações.

Os resultados nessa dimensão apontaram que não há grande vantagem obtida a partir de esforços conjuntos deliberados, como ações visando ao aprendizado coletivo. De fato, essa seria a maior necessidade de esforço do cluster.

Em grande parte dos países em desenvolvimento, afirma Schmitz (1997), a força propulsora para formação de clusters é endógena baseada na eficiência coletiva de uma comunidade. Essa força compreende a vantagem competitiva derivada de economias externas locais e ação conjunta.

A ação conjunta conscientemente exercida pode ser de dois tipos: firmas individuais cooperando (por exemplo, compartilhando equipamentos ou desenvolvendo um novo produto), ou grupos de firmas reunindo forças em associações empresariais, consórcios de produtores e assemelhados. Apesar desta pesquisa realizar um recorte na parte da cadeia referente aos rivais, aponta-se para a necessidade de concentrar os esforços conjuntos onde o ganho da ação conjunta deliberada possa ser positivo, encontrando os meios de governança 
adequados, de forma que a competição não venha a minar o senso colaborativo que alguns afirmavam ver como parte da cultura local.

\subsection{CLASSIFICAÇÃO DO CLUSTER PORTUÁRIO DE ITAJAÍ QUANTO AO ESTÁGIO DE DESENVOLVIMENTO}

De acordo com a pontuação obtida em cada um dos construtos, procedeu-se à classificação do estágio de desenvolvimento do cluster portuário de Itajaí. A nota balanceada dos cinco construtos foi de 7,59. Em uma escala de 0 a 10, seguindo a metodologia elaborada e utilizado por Cunha (2002) na classificação dos clusters catarinentes, o estágio inovativo proposto pelo autor englobaria os clusters cuja nota global fosse acima de 7,6. Nota-se assim que, de acordo com as premissas utilizadas, o cluster portuário catarinense encontra-se no limiar entre o estágio organizado e inovativo, como pode ser observado na tabela abaixo, elaborada a partir da opinião dos especialistas.

Tabela 4 - Resultado da avaliação do estágio de desenvolvimento do cluster portuário de Itajaí

\begin{tabular}{|c|c|c|c|c|c|}
\hline CONSTRUTO & VARIÁVEL & BAIXO & MÉDIO & ALTO & NOTA \\
\hline \multirow{3}{*}{ A. RELEVÂNCIA } & Contexto da Relevância & & & $\mathbf{x}$ & \multirow{3}{*}{8,95} \\
\hline & Centralidade do Cluster & & & $\mathbf{x}$ & \\
\hline & Qualificação dos Atores Críticos & & & $\mathbf{x}$ & \\
\hline \multirow{4}{*}{ B. DESEMPENHO } & Dinamismo Industrial & & & $\mathbf{x}$ & \multirow{4}{*}{8,77} \\
\hline & Exportações & & & $\mathbf{x}$ & \\
\hline & Lucratividade & & & $\mathbf{x}$ & \\
\hline & Competição Externa & & & $\mathbf{x}$ & \\
\hline \multirow{6}{*}{ C. COOPERAÇÃO (Propensão) e GOVERNANÇA } & Confiança & & & $\mathbf{x}$ & \multirow{6}{*}{6,87} \\
\hline & Competição/ Rivalidade & & $\mathbf{x}$ & & \\
\hline & Atmosfera Industrial & & & $\mathbf{x}$ & \\
\hline & Papel da Cultura & & & $\mathbf{x}$ & \\
\hline & Governança & & & $\mathrm{x}$ & \\
\hline & Competição Externa & & $\mathbf{x}$ & & \\
\hline \multirow{4}{*}{ D. ENTRELAÇAMENTO - INTEGRAÇÃO } & Integração Técnico-Produtivo & & $\mathbf{x}$ & & \multirow{4}{*}{7,10} \\
\hline & Desenvolvimento de Fatores & & & $\mathbf{x}$ & \\
\hline & Integração Tecnológico-Informação & & $\mathbf{x}$ & & \\
\hline & Suporte de Instituições & & & $\mathbf{x}$ & \\
\hline \multirow{3}{*}{ E. EFEITOS RESULTANTES DA AGLOMERAÇÃO } & Vantagens passivas ou de mera aglomeração & & & $\mathbf{x}$ & \multirow{3}{*}{6,25} \\
\hline & Ganhos derivados de ação conjunta (passivo) & & $\mathbf{x}$ & & \\
\hline & Ganhos de Ação conjunta deliberada & & $x$ & & \\
\hline \multicolumn{5}{|c|}{ AVALIAÇÃO FINAL ESTÁGIO CLUSTER } & 7,588 \\
\hline
\end{tabular}

Fonte: Elaborado pelos autores (2019).

Os resultados da classificação por notas revelaram que o cluster portuário da região de Itajaí atingiu um grau bem superior à média do modelo de aglomerado organizado, faltando muito pouco para ser considerado em estágio inovativo. Os destaques positivos estiveram em relevância, desempenho e integração, com as maiores notas na visão dos especialistas, enquanto propensão à cooperação e ganhos da ação conjunta deliberada podem demandar maiores esforços a fim de alçar o cluster ao estágio inovativo. 


\section{CONSIDERAÇÕES FINAIS}

Um cluster representa, para a região em que está inserido, emprego, renda, investimento e riqueza. Para as empresas que o compõem, pode representar, como explicitado no sistema de diamante de Porter (1990), o motor de competitividade que, de outro modo, atuando isoladamente, as empresas não obteriam.

O estudo realizado concentrou-se no cluster portuário na região de Itajaí, em Santa Catarina, com um recorte específico sobre as unidades portuárias locais. Com as inovações legais introduzidas pela Lei da Modernização dos Portos, de 1993, a atividade portuária anteriormente desenvolvida apenas pelos portos públicos, como é o caso do Porto de Itajaí, pôde ser explorada conjuntamente pelos terminais de uso privado, que hoje se situam ao seu redor.

Essa aglomeração portuária tornou-se referência nacional em termos de eficiência e produtividade, em vista do vertiginoso crescimento recente apresentado. Partindo-se da necessidade de aprofundar o conhecimento sobre elementos essenciais desse cluster, posicionou-se a pergunta de pesquisa para descobrir o seu estágio de desenvolvimento. A suposição inicial era de que, em vista do desempenho recente, poderia se tratar de um cluster em estágio inovativo, o mais avançado grau de desenvolvimento de clusters, segundo tipologia proposta por Cunha (2002) própria para economia em desenvolvimento.

O cluster portuário de Itajaí atingiu, segundo metodologia adotada, nota 7,59, em uma escala de 0 a 10, situando-se no limiar da classificação entre o estágio organizado e inovativo. Representatividade, desempenho e integração foram os indicadores mais positivos na avaliação dos especialistas, confirmando aspectos que chamaram a atenção para esse estudo. Ainda assim, ressalta-se que aspectos negativos relacionados à infraestrutura portuária de acesso no entorno, que já havia aparecido na literatura, foi também citado pelos especialistas, o que pode apontar para um possível fator de declínio se não sanadas as suas condições.

Quanto à cooperação entre as unidades portuárias, nota-se que há espaço para melhorias. A acirrada competição em nível global teve, na dimensão desempenho, uma contribuição positiva, mas na dimensão cooperação é apontada como o fator mais negativo, causando a deterioração das relações. Por se tratarem de competidores de uma mesma cadeia 
produtiva, certa competição é evidentemente esperada. No entanto, os resultados obtidos apontam para a necessidade de se avaliar instrumentos adequados de governança, com vistas a organizar possibilidades de cooperação em ações que beneficiem a eficiência coletiva (SCHMITZ, 1997), podendo-se mencionar como resultado do benefício conjunto a busca de novas linhas comerciais. A escolha de mecanismos de governança apropriados pode contribuir para acertar a dose adequada entre competição e cooperação entre as unidades.

O quinto indicador reforça essa análise. Os principais ganhos do cluster decorrem, segundo os especialistas, da mera proximidade geográfica, de forma passiva, o que significa que há margem para maiores ganhos advindos de uma atuação conjunta deliberada. Articular os esforços para integrar fatores técnico produtivo e tecnológicos de informação, cuja presença foi detectada em baixo estágio, pode contribuir para promover um alto nível tecnológico resultando em vantagens competitivas a todas as unidades.

O estudo realizado mostrou-se relevante em dois aspectos principais. Em primeiro lugar, confirma a utilização do instrumento de coleta para obtenção de um diagnóstico preliminar do estágio de desenvolvimento do cluster. Partindo-se de uma necessidade de obter, de forma rápida, uma visão geral desse cluster a partir da modernização dos portos, utilizou-se um método de coleta baseado no modelo prescritivo proposto por Cunha (2002). A pesquisa foi bem-sucedida ao capturar, de forma rápida, preciosas observações a respeito da aglomeração, o que se deve à criteriosa seleção de respondentes chave.

Ainda, essa aplicação expandiu a utilização do modelo antes restrita a clusters industriais tradicionais. Com alguns aprimoramentos realizados sobre $\mathrm{o}$ instrumento de coleta, pôde-se aplicá-lo sobre uma nova formação de cluster não tradicional, e em estágio recente de formação, o que aponta para o alto potencial de replicabilidade do instrumento de coleta sobre demais clusters da nova economia. Como ponto de melhoria, sugere-se a inclusão de questões que apontem para a fase do ciclo de vida do cluster (BRENNER; CHARLOTTE, 2011), a fim de evidenciar se possíveis fatores que, mesmo em estágio vertiginoso em cada dimensão, possam apontar para um caminho de declínio futuro.

Em segundo lugar, destaca-se o próprio resultado do diagnóstico obtido. Ao avaliar o cluster portuário de Itajaí no limiar entre os estágios organizado e inovativo, posiciona-se a experiência recente desse cluster no mais alto grau de desenvolvimento entre todos aqueles 
clusters catarinenses analisados por Cunha (2002) quando da propositura do modelo. Situar o cluster em uma escalada de desenvolvimento permite tanto utilizá-lo de referência a outros clusters da região quanto servir-se de referências de clusters mais avançados para aumentar sua potencialidade.

Em decorrência do método, não puderam ser obtidas avaliações mais personalizadas ou uma avaliação comparativa mais direta entre clusters portuários. Recomenda-se assim, para estudos futuros, o uso de métodos adicionais como entrevistas em profundidade ou estudo de casos comparados, considerando eventualmente a experiência portuária de outros países emergentes ou de referências mundiais, mediante aplicação de técnicas de benchmarking. Ainda, podem ser sugeridas aplicações do questionário desenvolvido a outros segmentos de negócios recentes, como tecnologia e indústria criativa, uma vez que foi identificado o alto potencial de replicabilidade do instrumento de coleta.

Por fim, destaca-se a importância de manter o acompanhamento sobre o desenvolvimento do cluster portuário de Itajaí com vistas a aprimorar constantemente o sistema do diamante proposto por Porter (1990). Como visto, o estímulo à rivalidade doméstica, obtido a partir da abertura dos portos à iniciativa privada, por meio da competição, expôs essas unidades portuárias ao mais alto nível de exigência da demanda, consagrando um cluster portuário de alto padrão de desempenho e relevância nacional. Não obstante, importantes aspectos de atuação conjunta e esforços de cooperação, como identificado do estudo, podem elevar os resultados obtidos dessa aglomeração.

\section{REFERÊNCIAS}

ANTAQ - Agência Nacional de Transportes Aquaviários. Estatístico Aquaviário. Disponível em: http://web.antaq.gov.br/Anuario/. Acesso em: 10.jun.2018.

BARAKAT, S. R. et al. Análise dos fatores condicionantes da gênese de clusters de empresas. Gestão \& regionalidade, 2017. v. 33, n. 98. Disponível em: <http://seer.uscs.edu.br/index.php/revista_gestao/article/view/3994/2142>.

BENITES-LAZARO, L. L.; MELLO-THÉRY, N. A. Empowering communities? local stakeholders' participation in the clean development mechanism in latin america. World development, 2019. v. 114, p. 254-266. Disponível em: <https://doi.org/10.1016/j.worlddev.2018.10.005>. 
BRASIL. Lei 12.815, de 05 de junho de 2013. Diário Oficial [da] República Federativa do Brasil, Poder Executivo, Brasília, DF, 05 jun. 2013. Disponível em: <http://www.planalto.gov.br>. Acesso em: 02 ago. 2013.

BRASIL. Lei 12.815, de 05 de junho de 2013. Constituição da República Federativa do Brasil. 1988. Disponível em:<http://www.planalto.gov.br>. Acesso em: 10 jul. 2012.

BRENNER, T.; SCHLUMP, C. Policy measures and their effects in the different phases of the cluster life cycle. Regional Studies, v. 45, n. 10, p. 1363-1386, 2011.

CABRAL, T. P. Porto-indústria e clusters portuários: uma análise comparativa. 2014. Disponível em: <http://repositorio.ufsc.br/bitstream/handle/123456789/123824/Monografia da Thaiane Cabral.pdf?sequence=1>. Acesso em: 31 jan. 2019.

CASAROTTO FILHO, N.; PIRES, L.H. Redes de pequenas e médias empresas e desenvolvimento. Atlas, 2001.

CUNHA, I. J. Modelo para classificação e caracterização de aglomerados em economias em desenvolvimento. [S.I.]: Universidade Federal de Santa Catarina, 2002.

DATAMAR. Liner services. 2017. Acesso em: 12 set. 2017

ENRIGHT, M. J. Regional clusters: what we know and what we should know. Innovation clusters and interregional competition. Springer, Berlin, Heidelberg, 2003. p. 99-129.

ENRIGHT, M. J. Regional clusters and economic development: A research agenda. Business networks: Prospects for regional development, 1996.

FRANCISCO, J. L.; BOTTER, R. C. Terminais de uso privado: um estudo da competição no estado de santa catarina. Revista eletrônica de estratégia \& negócios, 2017. v. 10, n. 11.

GIL, A. C. Métodos e técnicas de pesquisa social. São Paulo: Atlas, 2008.

LEVINE, D.M.; BERENSON, M.L.; STEPHAN, D. Estatística: teoria e aplicações-usando Microsoft Excel português. Ltc, 2005.

LIGUORI, E. et al. Development of a multi-dimensional measure for assessing entrepreneurial ecosystems. Entrepreneurship and regional development, 2018. v. 31, n. 1-2, p. 7-21. Disponível em: <https://doi.org/10.1080/08985626.2018.1537144>.

LÜBECK, R. M.; WITTMANN, M. L.; SILVA, M. S. Da. Afinal, quais variáveis caracterizam a existência de clusters, arranjos produtivos locais (apls) e dos sistemas locais de produção e inovação (slpis)? Revista ibero-americana de estratégia - RIAE, 2012. v. 11, n. 1, p. 120-151.

MALHOTRA, N. K. et al. Introdução à pesquisa de marketing. 2005.

MASCENA, K. M. C. De; FIGUEIREDO, F. C.; BOAVENTURA, J. M. G. Clusters e apl ' s: análise bibliométrica das publicações. RAE - Revista de Administração de Empresas - FGV/EAESP, 
2013. v. 53, n. 5, p. 454-468. Disponível em: <http://rae.fgv.br/rae/vol53-num5-

2013/clusters-apl's-analise-bibliometrica-publicacoes-nacionais-no-periodo-2000-2011>.

MATTAR, F.N.; OLIVEIRA, B.; MOTTA, S. Pesquisa de marketing: metodologia,

planejamento, execução e análise. Elsevier Brasil, 2014.

MINISTÉRIO DA INFRAESTRUTURA. Plano Mestre do Complexo Portuário de Itajaí (Sumário Executivo). Itajaí, 2018. Disponível em:

http://infraestrutura.gov.br/component/content/article/113-politica-e-planejamento-detransportes/5426-planos-mestres.html. Acesso em: 31 jan. 2019.

MYTELKA, L.; FARINELLI, F. Local clusters, innovation systems and sustained competitiveness. UNU/Intech Discussion Papers, 2000. n. October 2000, p. 7-37.

OLIVEIRA, K. D.; ALMEIDA, K.L.de; BARBOSA, T.L. Amostragens probabilística e não probabilística: técnicas e aplicações na determinação de amostras. Jerônimo Monteiro: Universidade Federal do Espirito Santo, 2012.

OLIVEIRA, T. M. V. De. Amostragem não probabilística: adequação de situações para uso e limitações de amostras por conveniência, julgamento e quotas. Administração on line, 2001. v. 2, n. 3, p. 1-7. Disponível em: <https://goo.gl/skzASC>.

PAOLIELLO, E. R. Análise dos aspectos concorrenciais no âmbito da lei 12.815/2013. Revista eletrônica direito e política, 2014. v. 9, n. 1, p. 26-50. Disponível em:

$<$ www.univali.br/direitoepolitica - ISSN 1980-7791>.

PINTO, R. A. Q. Proposta de modelo estratégico para consolidação de cluster industrial marítimo. 2016. Disponível em: <

https://repositorio.ufsc.br/xmlui/bitstream/handle/123456789/167819/342209.pdf?sequen ce=1\&isAllowed=y>. Acesso em: 31 jan. 2019.

PORTER, M. Competitive Advantage of Nations. Harvard Business Review, 1990. v. 1, n. 1, p. $1-14$.

PORTO DE ITAJAÍ - AUTORIDADE PORTUÁRIA. Relatório Estatístico do Complexo Portuário de Itajaí. Itajaí, 2018. Disponível em:

http://www.portoitajai.com.br/novo/estatisticas/199/Estat\%C3\%ADstica\%20de\%20Dezemb ro\%20de\%202018. Acesso em: 31 jan. 2019.

RAZMINIENE, K.; TVARONAVICIENE, M. Detecting the linkages between clusters and circular economy. Terra economicus, 2018. v. 16, n. 4, p. 50-65.

RENCK, E. Comparação Entre as Embarcações Pesqueiras que Praticam o Método de Cerco Construídas no Vale do Itajaí e Peru. TCC (graduação) - Universidade Federal de Santa Catarina. Campus Joinville. Engenharia Naval em 12/2014. Disponível em: https://repositorio.ufsc.br/xmlui/handle/123456789/127645. 
SALUME, P. K.; GUIMARÃES, L. D. O.; VALE, M. G. V. Análise de clusters: vantagens da abordagem baseada em dinâmica de sistemas. Desenvolvimento em questão, 2016. n. 37, p. 115-143.

SCHMITZ, H. Eficiência coletiva: caminho de crescimento para a indústria de pequeno porte. Ensaios Fee, 1997. v. 18, n. 2, p. 164-200.

ZELBST, P. J.; FRAZIER, G. V.; SOWER, V. E. A cluster concentration typology for making location decisions. Industrial management $\&$ data systems, 2010. v. 110, n. 6, p. 883-907. Disponível em: <http://www.emeraldinsight.com/doi/10.1108/02635571011055108>. 